\title{
Kein Sanitäter in der Not
}

Die Sache mit dem Alkoholkonsum scheint manchmal nicht ganz einfach: Einerseits werden etwa Rotwein immer wieder positive Effekte zugeschrieben - auch medizinische. Andererseits steigt das relative Risiko für einige Krebserkrankungen mit zunehmendem Alkoholkonsum. Laut dem vom Deutschen Krebsforschungszentrum herausgebrachten Alkoholatlas Deutschland 2017 liegt z. B. das Risiko für Mundhöhlen/Rachenkrebs bei Männern und Frauen mit einem Alkoholkonsum von 12-50 g pro Tag (115 ml Wein enthalten annähernd $10 \mathrm{~g}$ Alkohol) fast doppelt so hoch wie bei Menschen, die keinen Alkohol trinken. Außerdem kostet Alkohol die Gesellschaft viel Geld: Einnahmen durch die Alkoholsteuer von 3,2 Milliarden Euro im Jahr stehen direkte und indirekte Kosten für die Gesellschaft in Deutschland von 39 Milliarden Euro gegenüber.

Wie stark steigt das Risiko für Mundhöhlen/Rachenkrebs bei Männern und Frauen ab einem Alkoholkonsum von $>50 \mathrm{~g}$ pro Tag im Vergleich zu keinem Alkoholkonsum?

A ca. 3-fach

B ca. 5-fach

ca. 7-fach

Durch Ihre Teilnahme am Quiz erklären Sie sich d Der Buchstabe der richtigen Antwort ist Name Straße, Nr. PLZ, Ort

Was ich noch sagen wollte ...
Coupon bitte ausfüllen und abschicken an Springer Medizin Verlag GmbH Redaktion Im Focus Onkologie - Quiz 12/2017 Aschauer Straße 30, 81549 München oder nehmen Sie online teil unter www.springermedizin.de/im-focus-onkologie-quiz oder senden Sie uns eine E-Mail an kim.jene@springer.com oder senden Sie uns ein Fax an 089/20 304331113 Einsendeschluss: 05.02.2018
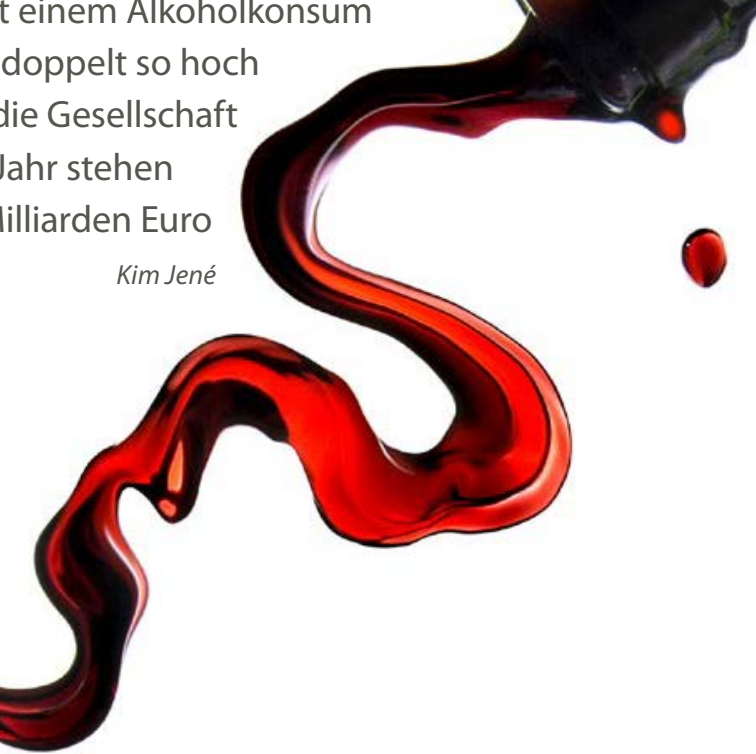